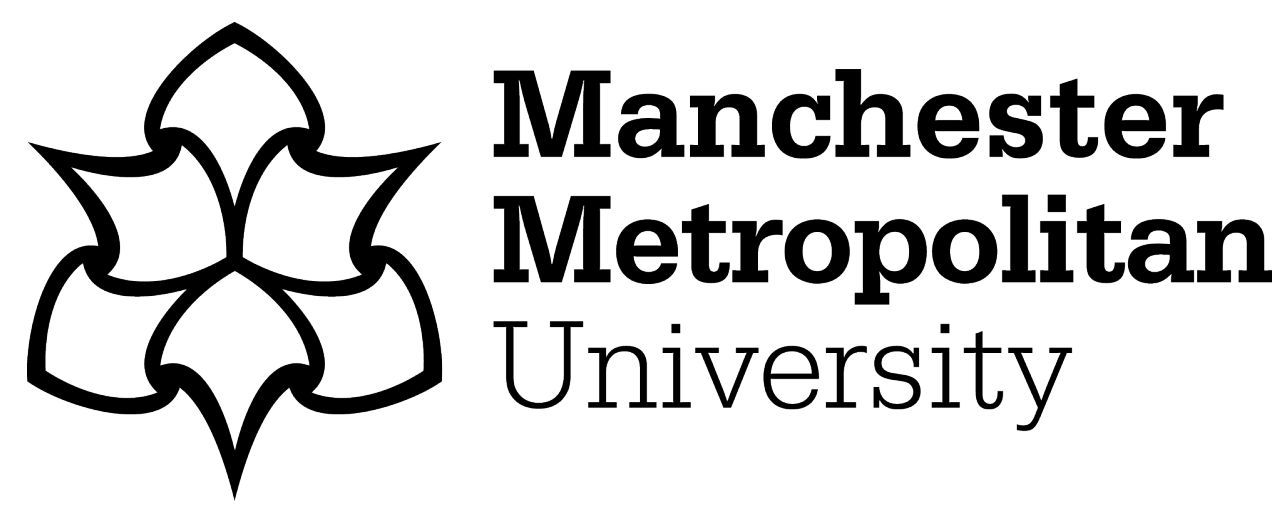

Archer, Dawn and Jagodzinski, P (2018) Applying (im)politeness and facework research to professional settings: An introduction. Journal of Politeness Research, 14 (2). pp. 167-178. ISSN 1612-5681

Downloaded from: https://e-space.mmu.ac.uk/621015/

Version: Accepted Version

Publisher: De Gruyter

DOI: https://doi.org/10.1515/pr-2018-0015

Please cite the published version 


\section{Applying (im)politeness and facework research to professional settings: An introduction}

Dawn Archer and Piotr Jagodziński

\section{LIAR IV}

The fourth Linguistic Impoliteness, Rudeness and Aggression conference (LIAR IV) was held at Manchester Metropolitan University (UK), from $12^{\text {th }}$ to $14^{\text {th }}$ July 2016 . The conference was designed to provide a platform for bringing together investigators who, although they might represent diverse theoretical, applied and/or practice-led traditions, nonetheless shared an interest in (im)politeness and facework (broadly conceived). By way of illustration, a plenary panel, organized by Hazel Price and Jack Wilson, demonstrated what can be achieved by bringing together scholars from diverse theoretical linguistic politeness traditions. The title of the plenary panel: Inter-/Intra-cultural (im)politeness in Court? A Case Study of Penelope Soto, indicates the participants' focus upon the bond hearing of the then 18-yearold from Miami (Florida) before Miami-Dade county judge, Jorge Rodriguez-Chomat. There were two primary foci: First, what linguistic (as well as extra-linguistic) factors led to an increase in the bond set (from $\$ 5,000$ to $\$ 10,000$ ), to Soto "being charged with criminal contempt of court and [then] sentenced to 30 days in the county jail" (Price and Wilson 2018: 1). Second, how the case was reported by (especially the online) media, and responded to by online commenters. Five of the presentations focussing upon the Soto case now appear in Volume 14(1) of the Journal of Politeness Research. Its aim is similar to that of the plenary panel, namely, demonstrating "the relative strengths of different approaches to politeness research using a single interaction as a case study" (Price and Wilson 2018: 1). They include classic approaches, such as Brown and Levinson (1987) and Goffman (1967, 1974, 1981) (see the papers by Grainger [2018], and O'Driscoll [2018] respectively), as well as semiotic, 
relevance theoretic, and critical discourse analyses of the case or its related datasets (see the papers by Wilson and Price [2018], Christie [2018], and Davies [2018]).

One of the invited plenary speakers at LIAR IV, Cliff Lansley, was representative of those at the conference who adopt a practitioner (rather than academic) perspective to (im)politeness and facework (broadly conceived). Lansley is Managing Director of the EIA Group, an international organization that works with a range of professionals to help them "develop the skills and competencies required to communicate effectively and compassionately" (https://www.eiagroup.com/about/). His talk focussed upon his team's work within the security sector and, in particular, their development of behavioural observation and engagement techniques designed to detect high-risk individuals (in, e.g., airport settings) as part of the EU-funded ARMLET training program (see Lansley et al. [2016] and Lansley et al. [2017]). As Lansley explained, this work has nonetheless involved collaborating with academics such as Dawn Archer in order to integrate the use of rapport into their behavioural analysis training for European air marshals and behavioural detection officers, thereby helping them to confirm and/or reject evidence-based hypotheses of potential mal-intent (see Archer et al., under review).

\section{Aims of this special issue, and summaries of the papers}

Lansley's plenary was mirrored by a number of 20 -minute presentations that shared his interest in enriching professional practice based upon a knowledge of and/or insights from facework and (im)politeness research, including changing the way interaction in professional contexts is perceived and conceptualized by the practitioners themselves. This special issue shares and expands upon this aim, by demonstrating how facework theorizing might be 
translated into the language of professional practice. Like the editors of Volume 14(1) of the Journal of Politeness Research, this special issue advocates, in addition, for greater dialogue between linguists who draw upon different approaches to study facework and (im)politeness phenomena: in our case, within professional settings. It argues, in turn, for (greater) dialogue between, first, (academic and commercial) researchers representative of disciplines beyond linguistics and, second, academics and practitioners representative of differing professions.

The first two papers making up this special issue are representative of the sessions within LIAR IV that sought to signal what facework and (im)politeness research can offer to call-centre practitioners (including those whose roles require them to provide training and development). Jagodziński and Archer bring together the latest research in marketing and linguistics in order to provide call centre practitioners (as well as researchers interested in call centre practice) with an innovative way of understanding a notion that is of crucial importance for their day-to-day institutional practice: customer experience. The paper begins with an introduction to this notion, and the various ways in which it has been conceptualized in marketing versus linguistic research. The authors then argue for an interactional understanding, such that customer experience comes to be seen as the co-constructed, situated achievement of both parties, rather than as something that is only achieved or projected by call centre agents adhering to institutional top-down prescriptions. They evidence this through a moment-by-moment analysis of excerpts from a real-life call centre interaction. They concentrate, in particular, on those occasions when the call centre agent fails to orient to the needs of the on-going interaction, seemingly because the institutional proscriptions take precedence. This allows them, in turn, to draw upon (in order to delimit) the notions of personal face and professional face in respect to call centre agents. They explain that "professional face comes about because of the metonymic relationship that emerges between the agent and the company s/he represents" such that the agent sees him- 
/herself and/or is recognized by the caller "as embodying the company" for the duration of the interaction (Jagodziński and Archer, this volume). Agents do not only have the option of "operating within their role...such that their professional identity (and hence professional face) is foregrounded", however, as they can also operate in ways that suggest their personal face is being foregrounded (or be situated in that position by the callers). The paper concludes with a number of recommendations for call centre business practitioners. This includes providing a working definition of customer experience that might be usefully operationalized in call centre training practice as a way of enabling call centre agents to exercise more interactional freedom and (according to Jagodziński and Archer) thereby offer a greater potential to achieve the best possible customer experience.

The second paper, by Harrington, analyses the in-house quality and training materials relating to a UK-based utilities company, with a view to identifying the potential rapportmanagement tensions that can arise from the discrepancies between institutional requirements and the affordances/confines of the debt-collection activity type. Harrington is particularly careful to dissect the interactional contradictions that are inherent in the helping you to pay us approach advocated by the call centre in question, such that "collectors are instructed to perform potentially face-threatening behaviours in order to collect debt, whilst simultaneously engaging in linguistic [face-enhancing] behaviour" designed "to develop rapport with the debtor" (Harrington, this volume). Having worked within this context, Harrington is aware of how "time and efficiency" pressures have probably led to "the need to perform" what are effectively "two tasks" - debt collection and customer service - in one interaction. She advocates, nonetheless, for the disbanding of the 'helping you to pay us' philosophy, thereby allowing them to "be treated as [the] discrete tasks" they are. Harrington methodically highlights the (potential) challenges created for collectors and debtors alike by mapping the call centre interactional pre- and proscriptions to Spencer-Oatey's (2005) 
rapport-management framework. The overarching conclusion stemming from the analysis corresponds with the findings of the first paper: that call centre employees should be given a significant amount of interactional freedom in order to be able to negotiate face-concerns in situ, rather than constantly having to orient to (often contradictory) institutional rules.

The third and fourth papers are not based upon presentations given at the LIAR IV conference in Manchester. Their inclusion serves as a useful reminder, nonetheless, of the value of facework and (im)politeness frameworks when seeking to make sense of identity and relational issues - especially in professional contexts. The third paper, by Chan, explores "the discursive processes involved in the construction and negotiation of face" with respect to 20 hours of business meetings relating to two Hong Kong-based companies (Chan, this volume). She is particularly interested in how the "interlocutors do facework while orienting to and actively constructing their interpersonal relationships": especially when it comes to occasions when subordinates engage in what are potentially "very face-threatening disagreements" with their superiors. Chan goes on to provide evidence for the claim that, via their facework, interlocutors are able to "simultaneously make identity claims and orient to the identity claims of each other in ways that either reinforce or challenge their interpersonal relationship". She notes how they might "reinforce or challenge not only their interpersonal relationship but... also orient to specific identity claims that are a crucial aspect of this relationship", thereby making "claims about their own and each other's identities within the team" (e.g., being the "one in charge, the expert who knows best, etc.”). They can "orient to these identity claims by either reinforcing and supporting ([as in] examples 1 and 2) or [by] challenging and rejecting them (as in examples 3 and 4)." Chan's analysis provides us with convincing evidence that identity work and facework go hand in hand and, as such, need to be analyzed in connection with each other - especially when analyzing disagreements. It provides support, in addition, for the claim that disagreements within a business context are 
not always face threatening (see, e.g., Angouri and Locher 2012; Rees-Miller 2000; Sifianou 2012). On the contrary, Chan's findings suggest that "even those disagreements that appear relatively face-threatening may in fact be identity enhancing and relationship maintaining ([as in] examples 1 and 2). Similarly, those disagreements whose illocutionary force appears to be less face threatening (as in examples 3 and 4) may actually challenge identity claims and interlocutors' interpersonal relationship[s]." Chan thus agrees with Chang and Haugh's (2011: 2960) call for "a theory of face which takes into account not only the interactional achievement of actions in a local context, but also the ongoing relationships of the participants, as well as particular aspects of the context". She agrees, further, with GarcésConejos Blitvich's (2013: 8) stance that "it is not possible to conceptualize face without taking identity into consideration", and with Miller's (2013: 76) position that "identity construction" thus needs to be "understood as a necessary process for mobilizing relational work".

The final paper of this special issue shares Chan's interest in both the possibility of facework being simultaneously face enhancing and face threatening and it also being linked with identity as well as relational issues. Archer and Willcox provide a fine-grained analysis of the facework engaged in by appraisers and appraised, when involved in Performance Appraisals (henceforth PAs) for a UK retail organization. In the process, they offer an adapted version of Archer's (2015) Facework Scale, as a means of accounting for the different faces in evidence in activities such as this, where facework is being used "more deliberately for self-presentation and impression management purposes" (Archer and Willcox, this volume). The authors argue that, in the case of PAs, this is because "at least one participant wants to make the best impression possible, and both participants probably want to present themselves in as positive a light as possible." Archer and Willcox go on to identify four faces associated with this activity type: professional face, company face, relationship 
face and competence face. Professional face and company face are distinguished from each other - contra to Jagodziński and Archer (this volume) - due to an industry-wide recognition that, when it comes to PAs in particular, it is possible to align one's work-based identity to either a professional body or the organization one works for (see, in particular, the 2017 Report for the Chartered Institute of Personnel and Development). Company face, then, relates "to that aspect of an individual's face which identifies (or is identified by others) with the company that employs them. These others may belong to the same company or sit outside the company" (Archer and Willcox, this volume). Professional face, in contrast, "relates to the extent to which X identifies themselves and/or others with their profession”, and personal face, "to X's identification of self and/or other[s] in a workplace setting beyond their company role or their professional role" (cf. Jagodziński and Archer, this volume). The author's understanding of relationship face is influenced by a person's attempt to project a positive image of themselves (and sometimes others) in this context, with the aim of being perceived as "likable", "cooperative", "agreeable", etc. This aspect of face is in play, for example, when an appraiser seeks an explanation from the appraised as to whether/how/why they are the right "fit" (given the composition of the organization and/or group). Competence face “relates to a person's want to signal and/or be identified with his/her accomplishments, reputation, etc." such that they focus upon their experience, capabilities, etc. Within the PA context, it thus "aligns with identity-related" topics "such as how good I am at my job". Archer and Willcox go on to show how interlocutors within the PAs used facework strategies that not only "emphasized different or multiple facets of face on both a professional and personal level" but also sought "to safeguard/support their working relationships", at the same time as enhancing their own perceived competence. They show, further, how such facework can also have identity and relational implications for specific colleagues who are not present (thereby leading to a discussion of third-person oriented facework). The authors 
then use their findings "to argue that" many "employers and their employees would benefit from having an understanding of face(work), and briefly discuss the training implications" for PAs if face(work) notions were introduced (Archer and Willcox, this volume).

\section{A summary of what professional practitioners can gain from this special issue}

The four papers within this special issue are interventionist (cf. Antaki 2011: 8) in orientation (albeit to differing degrees). By this we mean they seek to engage in a dialogue with practitioners who are themselves representative of various professions, with the aim of offering insights into how communication in their professional contexts might be better understood and, potentially, improved, thereby also improving their professional practices. By way of illustration, Archer and Willcox (this volume) have adapted - as a means of (more effectively) applying - Archer's (2015) Facework Scale to the PA context, and gone on to provide interactional evidence for how facework might have implications for both the appraiser's and appraised's competence and credibility. By orienting to the types of face they suggest are at play in PAs, the authors argue that practitioners should be able to increase the likelihood of performing a successful appraisal (not least because any potential ambiguities or misunderstandings can be reduced, and clarity and transparency between the participants can be increased). Willcox's role as a consultant for the HR industry means that he is in a good position to be able to test the viability of this model with future clients (cf. Section 4).

Harrington, and Jagodziński and Archer, also make a number of recommendations in their papers, based (in part) on Harrington's and Jagodziński's work-related experience of the activity types under investigation. In both cases, their recommendations are aimed at call centre practitioners: especially those who engage in service encounters as part of their role (or are responsible for training others to do so). It is worth noting that both sets of authors 
advocate for agents to be given more interactional freedom (rather than being tied too rigidly to institutional protocols). From Harrington's perspective, such interactional freedom would offset to some degree the difficulties associated with a collector's need "to execute debt collection and customer service tasks in the same call'". By this she means having to "simultaneously perform relational work that sustains or promotes positive relationships" whilst "executing a transaction that necessitates a high degree of assertion and imposition", sometimes using prescribed (but nonetheless) "falsely facilitative rapport-building devices" in the process (e.g., "using silence to appear face-maintaining whilst indirectly controlling the unfolding discourse"). As Harrington is at pains to make clear, she does not mean to suggest "that relational talk and transactional talk are...mutually exclusive". Nonetheless, "two communicative goals that demand oppositional approaches to negotiating interpersonal relations can be challenging to satisfactorily reconcile in practice", especially for a sector that is notorious for its "high staff attrition rate" (Harrington, this volume). ${ }^{1}$

In the conclusion to their paper, Jagodziński and Archer argue that agents (especially those tasked with dealing with, e.g., complaints) will be in a stronger position to "focus on the interpersonal as well as the transactional" once they have been unshackled "from the topdown approach". They argue, further, for the usefulness of aforementioned notions such as professional face and concepts such as reality paradigms (Archer, 2011b) in a training context. They believe, for instance, that the notion of professional face would help "agents (in particular) separate their personal face from their professional duties", once operationalized (Jagodziński and Archer, this volume). They also claim that an agent would be able to "put themselves metaphorically in their customer's shoes more effectively" if they were trained to

\footnotetext{
${ }^{1}$ One reason for such high attrition rates is the high levels of stress associated with agents having to repeatedly regulate their emotions, so that they do not respond inappropriately to the face attacks of calling customers, debtors, etc. (see, e.g., Grandey et al. 2004; Wegge et al. 2007).
} 
(linguistically) spot when a caller's behaviour towards them pointed to a divergent perception "of how the world works" on their part. Jagodziński and Archer posit the use of face-threat mitigation exercises involving real-life examples, with respect to the latter: "the aim being to find ways of interacting that would better match [an] interlocutor's mindset, and hence better serve the customer service ideal (whilst also keeping in mind the company's needs)".

\section{The special issue's theoretical contribution(s)}

Chan's contribution to this special issue is the least interventionist, in practice-based terms. It manages to offer "a better understanding of the discursive processes involved in the construction and negotiation of face, identity, and relationships in Chinese business interactions" nonetheless. As such, it provides a practical "illumination of routine institutional work" (Antaki 2011: 6). This paper's main strength, however, relates to the theoretical contribution it makes. Simply put, it argues for "a theory of face which takes into account not only the interactional achievement of actions in a local context, but also the ongoing relationships of the participants, as well as particular aspects of the context" (Chan, this issue, following Chang and Haugh, 2011: 296). It then makes determined moves towards evidencing how interlocutors actually "do identity work while doing facework" in their business meetings. Chan's interactional, constructivist approach (theoretically speaking) chimes, in particular, with Archer and Willcox's understanding of face(work) and its links with self-presentation and impression management (see Section 2, above). There is also overlap in respect to the two papers when it comes to understanding that some interaction can be simultaneously face enhancing and face threatening. Both can thus be seen as answering Garcés-Conejos Blitvich's (2013) “call for more empirical studies on face and identity” (Chan, this issue). They also serve to extend the "current debate about these issues" in the (im)politeness and facework literature with respect to interpersonal relationships (in the case 
of Chan), relationship management (in the case of both) and their links with, for example, perceptions of credibility and competence (in the case of Archer and Willcox).

Jagodziński and Archer's focus on the under-theorized yet paramount concept of customer experience (especially in contemporary call centres) ensures that this paper also makes an important theoretical contribution. This contribution, understood very broadly, boils down to a seemingly trivial, yet fundamental observation that customer experience is primarily an interactional phenomenon in which situated language use plays the central role. This constitutes the reason why the authors advocate for more emphasis being placed on the role of language in marketing (theoretical) approaches to customer experience. The authors advocate that the role should not be based on seeing the language as a kind of "currency" exchanged between the agent and the caller during a telephone service encounter, but, rather, as a means of fostering interpersonal relationships between them, thereby contributing to customer satisfaction, loyalty and quality improvement in customer service. If applied to marketing literature theorizing, such an approach could potentially prove to be a gamechanger for the call centre industry as a whole. On a more linguistic-theoretical level, Jagodziński and Archer (this volume), as well as Harrington (this volume), provide evidence that both relational and transactional talk are not mutually exclusive (cf. Félix-Brasdefer 2015) in a call centre service encounter activity type. On the contrary, the authors collectively argue that facework and identity work are both indispensable when it comes to "doing transaction" over the telephone.

\section{Issues to overcome if academics and professionals are (to continue) to come together}

One motivation for this special issue is to promote the use of linguistics - and especially facework models and theories - in a range of professional settings. This has been made 
possible because the authors have had (or continue to have) access to data and/or institutions that usually prove to be inaccessible to academics. With respect to three of the papers in this special issue, some of the authors - Harrington, Jagodziński and Willcox - have been able to draw upon their direct experience of working within and/or consulting for those involved in the activity types under investigation. Some types of data can still prove difficult to access, nonetheless. Calls that have been recorded for monitoring and training purposes (as opposed to research) are especially likely to be prohibited, due to issues of confidentiality and data protection compliance, etc. The work reported in this special issue thus adds to a limited number of recent studies that have managed to overcome these "methodological hurdles" (as Hood and Forey, 2008: 390 label them). Other hurdles still remain, however. They include the need to be open to different practices when it comes to engaging and then reporting on and/or publishing research. Within much academic research, it is normal to provide theoretical underpinnings for one's preferred approach. This theoretical need to situate one's work may not be relevant to commercial researchers, however. Commercial researchers may thus write up their work in a very different way to academics. They may also find academic journal papers (even ones aimed at them and/or their fellow practitioners) to be unduly wordy for their commercial tastes and/or inaccessible to them in other ways (because of the proliferation of academic buzz terms, for instance). Journals have a part to play here, by being willing to publish work that is not only transdisciplinary in academic terms, but also transdisciplinary in terms of academic versus professional practices. Additional ways to overcome what effectively constitute (potential) language barriers include academics, commercial researchers and practitioners working together to ensure they become familiar with each other's communities of practice (Wenger, 1998). Archer's work with Willcox (this volume) and with Lansley (one of the invited plenary speakers at LIAR IV) with respect to his group's work in airport settings (see, e.g., Lansley et al, 2016, 2017; Archer et al., under 
review) provides us with two examples relating to the field of (im)politeness and facework. We hope that this special issue might also foster others.

\section{References}

Angouri, Jo \& Miriam Locher. 2012. Theorising disagreement. Journal of Pragmatics 44(12). 1549-1553.

Antaki, Charles. 2011. Six kinds of applied conversation analysis. In Charles Antaki (ed.), Applied conversation analysis, 1-14. London: Palgrave.

Archer, Dawn. 2011. Libelling Oscar Wilde: The case of Regina vs. John Sholto Douglas. Journal of Politeness Research: Language, Behaviour, Culture 7(1). 73-99.

Archer, Dawn. 2015. Slurs, insults, (backhanded) compliments and other strategic facework moves. Language Sciences 52. 82-97.

Archer, Dawn \& Phil Willcox. (this issue). The faces at play in performance appraisals: With a focus upon a UK retail organization.

Archer, Dawn, Cliff Lansley \& Aaron Garner. (under review). The value of linguistics in assessing potential threats in an airport setting. In Lesley Jeffries \& Jim O’Driscoll (eds.) Handbook of language in conflict. London: Routledge.

Brown, Penelope \& Stephen C. Levinson. 1987. Politeness: Some universals in language usage. Cambridge: Cambridge University Press.

Chan, Angela (this issue). Exploring face, identity and relationship management in disagreements in business meetings in Hong Kong.

Chang, Wei-Lin M. \& Michael Haugh. 2011. Strategic embarrassment and face threatening in business interaction. Journal of Pragmatics 43(12). 2948-2963. 
Chartered Institute of Personnel and Development (CIPD). 2017. HR Professionalism: What do we stand for? Research Report [online]. Available at:

https://www.cipd.co.uk/Images/hr-professionalism-what-do-we-standfor_2017_tcm18-17960.pdf. (Accessed 28 July 2017).

Christie, Christine. 2018. The indexical scope of adios: A relevance theoretic analysis of discursive constructions of gender and institutions and their impact on utterance interpretation. Journal of Politeness Research 14(1). 97-120.

Davies, Bethan. 2018. Evaluating evaluations: What different types of metapragmatic behaviour can tell us about participants' understandings of the moral order. Journal of Politeness Research 14(1). 121-154.

Félix-Brasdefer, J. César. 2015. The language of service encounters. Cambridge: Cambridge University Press.

Garcés-Conejos Blitvich, Pilar. 2013. Introduction: Face, identity and (im)politeness. Looking backward, moving forward: From Goffman to practice theory. Journal of Politeness Research: Language, Behaviour, Culture 9(1). 1-33.

Goffman, Erving. 1967. Interaction ritual: Essays in face-to-face behavior. Chicago: Aldine.

Goffman, Erving. 1974. Frame analysis: An essay on the organization of experience. Chicago: Northeastern University Press

Goffman, Erving. 1981. Forms of talk. Philadelphia: University of Pennsylvania Press.

Grainger, Karen. 2018. "We're not in a club now": A neo-Brown and Levinson approach to analyzing courtroom data. Journal of Politeness Research 14(1). 19-38. 
Grandey, Alicia, David Dickter \& Sin Hock-Peng. 2004. The customer is not always right: Customer aggression and emotion regulation of service employees. Journal of Organisational Behaviour 25. 397-418.

Harrington, Leigh. (this issue). "Helping you to pay us": Rapport management in debt collection call centre encounters.

Hood, Susan \& Gail Forey. 2008. The interpersonal dynamics of call-centre interactions: Coconstructing the rise and fall of emotion. Discourse and Communication 2. 389-409.

Jagodziński, Piotr \& Dawn Archer. (this issue). Co-creating customer experience through call centre interaction: Interactional achievement and professional face.

Lansley, Cliff, Aaron Garner, Dawn Archer \& Sori Losni. 2016. The impact of SCAnR training for Air Marshals to increase accuracy of real-time lie/truth decisions. Report for ARMLETT (Romania).

Lansley, Cliff, Aaron Garner, Dawn Archer, Ramona Dimu, Christi Blanariu \& Sorin Losnita. 2017. Observe, target, engage, respond (OTER): High-stake behaviour analysis using an integrated, scientific approach within an airport context. White Paper Series: EIA/SRI/OTP.

Miller, Elizabeth R. 2013. Positioning selves, doing relational work and constructing identities in interview talk. Journal of Politeness Research: Language, Behaviour, Culture 9(1). 75-95.

O’Driscoll, Jim. 2018. Dances with footings: A Goffmanian perspective on the Soto case. Journal of Politeness Research 14(1). 39-62.

Price, Hazel \& Jack Wilson. 2018. Applying politeness research: An introduction to the Soto Data. Journal of Politeness Research 14(1). 1-17. 
Rees-Miller, Janie. 2000. Power, severity, and context in disagreement. Journal of Pragmatics 32. 1087-1111.

Sifianou, Maria. 2012. Disagreements, face and politeness. Journal of Pragmatics 44. 15541564.

Spencer-Oatey, Helen. 2005. (Im)politeness, face and perceptions of rapport: Unpacking their bases and interrelationships. Journal of Politeness Research (1). 95-119.

Wegge, Jurgen, Joachim Vogt \& Christiane Wecking. 2007. Customer-induced stress in call centre work: A comparison of audio- and videoconference. Journal of Occupational and Organizational Psychology 80. 693-712.

Wenger, Etienne. 1998. Communities of practice: Learning, meaning and identity. Cambridge: Cambridge University Press.

Wilson, Jack \& Hazel Price. 2018. Courtroom data and politeness research: A case for neoPeircean semiotics in interpersonal pragmatics. Journal of Politeness Research 14(1). $63-96$. 